\title{
Los nuevos retos al marco normativo y a la seguridad en el ámbito local
}

\author{
Juan-Cruz Alli Turrillas \\ Doctor en Derecho \\ Profesor titular de Derecho administrativo (UNED)
}

\begin{abstract}
Sumario: I. LA CUESTIÓN DE LA SEGURIDAD. 1. Introducción general. 2. Algunas cuestiones conceptuales. 2.1. Riesgos y amenazas frente a la seguridad nacional. 2.2. La cuestión de la defensa militar y la seguridad. 2.3. Los riesgos y amenazas a la seguridad ciudadana lo son, en gran medida, a la seguridad nacional. 2.4. El ámbito más estricto de la seguridad ciudadana y pública. 2.5. Las consecuencias sobre las fuerzas policiales y militares. 3. El marco normativo ante la seguridad. 3.1. Constitución y Ley orgánica de fuerzas y cuerpos de seguridad. 3.2. La normativa vigente sobre la seguridad. 3.3. El marco europeo. 4. La necesidad de una verdadera integración del sistema de seguridad. II. CUESTIONES EN TORNO A LAS COMPETENCIAS LOCALES EN SEGURIDAD. 1. Los retos de la seguridad local. 1.1. Las cifras de la (in)seguridad en España. 1.2. Las competencias locales y su posible reforma. 2. La necesidad de una transformación en la seguridad local. III. EN CONCLUSIÓN.
\end{abstract}

\section{LA CUESTIÓN DE LA SEGURIDAD}

\section{Introducción general}

Las transformaciones del mundo raramente son revolucionarias y, más bien, se producen paulatinamente por una acumulación crítica realidades sociales y económicas, continuadas, luego, de otras conceptuales o de mentalidad. Acumulación que provoca —en ocasiones necesariamente, otras no tanto-, esos estallidos o cambios políticos «revolucionarios». Momentos que, posteriormente en manos de historiadores sirven, entre otras cosas, para marcar las épocas históricas.

Dejando de lado el debate de si nos encontramos ante la revolución de la postmodernidad, lo que sí parece más o menos claro es que, en la última década de los años 90 se han consolidado una serie de cambios políticos (caída del muro de Berlín, ausencia de la lucha entre bloques políticos antagonistas), sociales (relativismo político, sociedad de la información, pluralidad cultural, etc. $)^{1}$, ideológicos y técnicos (tecnologías de la información, sociedad red, globalización) junto, finalmente, con otros económicos (todos los que vienen derivados de las nuevas formas de producción y de la sociedad del conocimiento y de la globalización) de indudable trascendencia. Y que, todos ellos unidos, han dado lugar a una «nueva era» cuyo comienzo tenía, hasta hace bien poco, como símbolo distintivo, la caída del muro de Berlín.

\footnotetext{
${ }_{1}$ M. CASTElls, La era de la información: economía, sociedad y cultura, volumen III (El poder de la identidad), Alianza, 1998.
} 
Todo ello había supuesto una lenta pero perceptible transformación de los moldes sociales y de las organizaciones estatales. Los Estados-nación se encontraban con numerosos retos que dificultaban su papel. Pero aún nada estaba muy cambiado. Porque parece que cuando realmente se ha producido el cambio un poco más de una década después de los hechos descritos. Quienes no se hubiesen dado cuenta de que el mundo cambiaba, como así estaba ocurriendo, han tenido una nueva e insoslayable oportunidad el 11 de septiembre de 2001, verdadero y trágico comienzo del nuevo siglo; con sus terribles ecos de Indonesia (2002), Estambul (2003), Madrid (2004) y Londres (2005), entre otros muchos atentados producidos por el fenómeno conocido con el nombre de «nuevo terrorismo» ${ }^{2}$. Aunque la reiteración que se ha hecho y se hará de estas fechas y sus consecuencias, puede resultar tediosa, es cierto que todos estos días aciagos tienen una enorme trascendencia. No sólo - y obvio es decirlo - por su coste humano, sino también por la impresión visual y subjetiva que produjo sobre la seguridad, no sólo la nacional, sino para la seguridad ciudadana, existencial y vital de una prepotente sociedad occidental. Y, además, por haber determinado el aparente comienzo en una nueva época, en la que los riesgos a la seguridad han pasado, realmente, al primerísimo plano de las sociedades occidentales y del todo el mundo ${ }^{3}$.

Ante esta realidad, el actor tradicional en toda la civilización desde la Edad media, es decir, el Estado, está teniendo que acometer una serie de cambios que todavía no se sabe en qué van a acabar. Hace un tiempo se hablaba de la muerte del Estado y de su profunda crisis, al quedar debilitado tanto por arriba (importancia de las entidades supraestatales, globalización empresarial, movimientos sociales informales, ONGs, etc.) como por abajo (federalismo, separatismos, movimientos ciudadanos, etc.). Señala FukUYAMA, a modo de resumen, que la paradoja actual es que el Estado se ha quedado grande para lo pequeño y pequeño para lo grande ${ }^{4}$. Pero parece que, si bien bajo una cierta situación de crisis, el Estado continúa siendo un protagonista esencial, al estar dotado de grandes medios humanos y personales, de poder, de legitimidad democrática, de justificación política, etc ${ }^{5}$. Y, en medio de todo ello, además se nos aparece como una realidad esencial. El Estado tiene su origen y siempre se le ha exigido por sus súbditos, o ciudadanos, que cumpla el deber de dotarles de seguridad. Aquí es donde vamos a incidir.

Este trabajo va a partir de esta transformación para estudiar, en primer lugar, los conceptos que se manejan al hablar de la seguridad. Tras ello, en segundo lugar, examinaré si nuestro marco normativo está suficientemente capa-

\footnotetext{
${ }^{2}$ W. Laqueur, La guerra sin fin. El terrorismo en el siglo XXI, Destino, 2003.

3 Todo ello en J. JoRdán y J. L. CALvo, El nuevo rostro de la guerra, Eunsa, 2005, in toto, y R. KAGAN, Poder y debilidad, Europa y Estados Unidos en el nuevo orden mundial, Taurus, 2003.

${ }^{4}$ F. Fukuyama, La construcción del Estado, sine qua non, ediciones B, 2004.

${ }^{5}$ Algunas de sus consecuencias jurídicas están expuestas en: A. JARILlO, «Globalización: concepto y papel del Estado», en Boletín de la Facultad de Derecho 18 (2001), 215 y ss.
} 
LOS NUEVOS RETOS AL MARCO NORMATIVO Y A LA SEGURIDAD EN EL ÁMBITO LOCAL

citado para acoger los nuevos retos y paradigmas teóricos a los que se enfrenta el Estado, tanto en general, como en el estricto ámbito de la seguridad ciudadana y, en concreto de la seguridad local. Finalmente haré una serie de propuestas modificativas sobre el sistema vigente, centrándonos en todo lo relativo al régimen municipal, por ser la materia estricta del este estudio.

No pretendo, como se colegirá de su lectura, hacer un estudio dogmático-jurídico sobre problemas competenciales o de interpretación de la legalidad, sino llamar la atención sobre una realidad en transformación a la que las normas apenas están haciendo eco y que, en todo caso, supone todo un cambio de entorno en las operaciones que, día a día y junto con las tradicionales, han de hacer nuestros policías - sean del tipo que sean- para garantizar la seguridad, la paz y el buen orden ciudadano.

\section{Algunas cuestiones conceptuales}

\subsection{Riesgos y amenazas frente a la seguridad nacional}

Es preciso, en primer lugar, hacer una aproximación a los conceptos para, entre otras cosas, poder señalar que la situación de crisis en la que nos encontramos - crisis como momento de mutación, no como convulsión previa al colapso ${ }^{6}$ - Pues si bien acepto esa afirmación, también me parece que una de las consecuencias más claras de este difícil y complejo mundo en el que vivimos es que ha dejado de ser el mundo de la seguridad - ahora no en sentido estricto de seguridad ciudadana-, de los conceptos, de las certidumbres, para haber alumbrado una nueva era de incertidumbre perpetua. Es una era en la que muchas de las realidades más normales parecen haberse hecho invisibles, inaprensibles, difíciles de comprender y, por ello, de conceptuar? ${ }^{7}$. Los conceptos que veníamos utilizando parece que no sirven o que han quedado demasiado tocados por tantos años de «duda universal», hoy corroborada por los hechos; de tal manera que se han convertido en inútiles. Ejército, defensa, policía, seguridad, Estado son ideas que obedecen a unas realidades que sufren estar en una suerte de crisis profunda, moldes conceptuales que no parecen capaces de recoger las nuevas realidades que los atenazan.

Por otro lado, muchas realidades — guerra contra el terror, emergencia nacional, inseguridad, Patriot act, etc.— también se nos aparecen como conceptos vagos, eufemísticos, dificultosos que - en ocasiones como coartada, en otras como forma de predisponer al oyente- esconden realidades de difícil comprensión, cuando no son verdaderas «patentes de corso» para que el Estado continúe actuando con su brazo poderoso.

\footnotetext{
${ }^{6}$ Aunque así es para algunos, L. ARdANT DU PLESSIS, La tercera guerra ha comenzado, Inédita, 2004.

7 D. InNERARITY, La sociedad invisible, Espasa, 2004
} 
Por todo ello me parece interesante someter a un cierto análisis crítico los conceptos que más vamos a utilizar: seguridad, riesgo, amenaza, defensa. Y esto porque, como señala DE CASTRO, la dificultad para definir uno u otro es muy grande, por tratarse de un tema tan espinoso ${ }^{8}$. Hoy día, además las ideas de seguridad pública y seguridad ciudadana, siendo parecidos, también cuentan con matices diversos e interesantes. ¿Qué es, por tanto y en primer lugar, la seguridad?

La seguridad es una situación en la cual todo está en su lugar porque se está exento de todo riesgo, amenaza o peligro. Esto genera, inmediatamente, una percepción subjetiva (que es la otra faceta del término): la confianza, la certeza de estar situado en un lugar fuera de peligro9. De hecho este elemento subjetivo es, hoy día, esencial. La globalización comunicativa y el reinado de la imagen provocan sentimientos de inseguridad ante atentados, crímenes, etc., cuando, en puridad, sus cifras son bajas en proporción a la población e, incluso, en comparación a otros periodos históricos pasados. Este concepto nos lleva, por tanto, a otros de indudable importancia:

Riesgo: un riesgo, es la contingencia o proximidad de un daño. En cierto modo el riesgo es una situación involuntaria: se está en una situación de riesgo solo por el mero hecho de tener una posición cercana a ciertos peligros (que pueden ser situaciones, países, personas). El riesgo es un peligro genérico y, en cierto modo, indeterminado.

En cambio, amenaza es el indicio o presagio en la inminencia en algún peligro o situación desagradable. Es un riesgo determinado, concretado en los sujetos. Por eso, jurídico-penalmente es un riesgo advertido provocativamente por personas y constitutivo de delito. En todo caso si esa amenaza no se convierte en realidad dañosa, no se materializa, es porque alguien la evita (es por ello que la información y la actuación policial está dirigida a evitarlo, y a perseguirlo una vez producido).

Entre riesgo y amenaza existe una doble relación. Por un lado la amenaza es el anuncio personal de un riesgo; es decir, una amenaza es un riesgo provocado por alguien (así se dice que sufres o padeces una «situación amenazante» o que te «están amenazando»). Por otro lado entre ambas suele existir, también, una relación de gradación: El riesgo, genérico e indeterminado, es el estadio previo la amenaza, más inminente y claro ${ }^{10}$. Igualmente los términos paz y seguridad parecen guardar similitudes. Pero no es del todo

\footnotetext{
${ }^{8}$ M. C. Hurtado Martínez, Concepto y causas de la inseguridad, Universidad de Castilla-La Mancha, Cuenca, 1999, p. 2.

${ }^{9}$ Para todo ello, M.- J. IzU Belloso, La policía foral de Navarra, Gobierno de Navarra, 1992.

${ }^{10}$ También hay quien sitúa el peligro en medio de ambos, pero no podemos detenernos más ahí. M. A. Ballesteros Martín, Fundamentos de la estrategia del siglo XXI, en Monografías del CESEDEN 67 (2003).
} 
LOS NUEVOS RETOS AL MARCO NORMATIVO Y A LA SEGURIDAD EN EL ÁMBITO LOCAL

así. La paz era definida, primero, como la «tranquilidad en el orden»; luego como la mera ausencia de guerra; más actualmente es entendida como «sosiego y buena correspondencia entre las personas». Desde el primer punto de vista paz y seguridad serían términos similares (tranquilidad en el orden). Pero desde el segundo, tienen poco que ver (pues una guerra no tiene, estrictamente, por qué amenazar nuestra seguridad; o, como suele ser más común, hay inseguridades que no amenazan la paz). Finalmente desde el tercer punto de vista, paz y seguridad no tienen nada que ver, pues la paz es un concepto más amplio. Por todo ello se puede estar muy seguro (con la seguridad del poderoso, siempre endeble, por otra parte) y, en cambio, no tener ni estar en paz. Es más habitual, no obstante, estar en paz (militar), pero con graves riesgos e incluso amenazas serias a la seguridad nacional y, por supuesto, ciudadana. Cuando hay una amenaza muy seria a la seguridad ciudadana se habla, por eso de un peligro de ruptura en la paz social (o en la paz civil).

\subsection{La cuestión de la defensa militar y la seguridad}

Es evidente que actualmente muchos retos de la seguridad estatal son mucho más graves que la mera inseguridad ciudadana y lindan con lo que podríamos englobar bajo la idea de la «seguridad nacional»o, si se quiere, en la defensa. Por eso nos queda un último estadio. ¿Qué es la defensa? Se ha definido como una acción, una actividad, incluso una actitud, cuyo objeto es evitar, precisamente, todo riesgo, amenaza o peligro. ¿Y a qué? Pues resulta que, precisamente, a nuestra seguridad personal o colectiva. Porque en estas nuevas realidades los enemigos combaten con medios asimétricos ${ }^{11}$. Es nuestra defensa militar frente a su amenaza a nuestra seguridad individual (vida, libertad, derechos, valores, etc.). Este es el modelo que la profesora KALDOR denomina «las nuevas guerras»: guerras de los valores antiguos contra los nuevos ${ }^{12}$.

En fin, resulta que la defensa es, precisamente, la defensa de la seguridad, en concreto de la nacional. Porque es esa seguridad nacional la que hoy día está amenazada y en riesgo - lamentablemente real- por parte tanto de esas «nuevas» formas de guerra, tanto aquí como en derredor, como por el terrorismo internacional. De hecho uno de los problemas que tiene hoy día la denominada «defensa nacional»y, con ella, las Fuerzas Armadas es la definición de su papel, de su misión y función. Pues el problema actual es de un profundo solape entre ejércitos, militares, y cuerpos de seguridad y policías. En definitiva, el principal problema es la defensa de la seguridad. Es así pues que seguridad nacional y seguridad pública (e incluso ciudadana) se compenetran, se necesitan, se exigen mutuamente.

Vayamos un poco más lejos. La defensa era medible en términos de di-

\footnotetext{
11 J. Jordán y J. L. CALvo, El nuevo rostro de la guerra, cit., pp. 41 y ss.

12 M. KALdoR, Las nuevas guerras, Tusquets, 2001, pp. 64 a 88, entre otras.
} 
suasión y de paz, de ausencia de amenazas y de seguridad; pero la seguridad es mucho más compleja. La defensa servía para evitar la guerra y ésta finalizaba con la victoria, clara, contundente. Pero la seguridad no llega a esa victoria, puesto que se tiene que limitar a evitar daños mayores o a congelar los efectos de la inseguridad. De ahí que estas, antes denominadas, «nuevas guerras» tengan una cierta tendencia a ser farragosas, largas, tediosas, difíciles de medir y de saber dónde acaban, ni siquiera cuándo empiezan ${ }^{13}$.

Se pensará que muchos de los términos utilizados son conceptos eminentemente militares. Y así es. Pero es que si la defensa nacional ya tenía implicaciones muy amplias, más las tiene la seguridad nacional. Hoy día es evidente que es más urgente actuar por la seguridad nacional y que esta tiene un altísimo componente policial y ciudadano. Los grandes atentados, antes citados, cometidos por la jihad en tantos lugares son la manifestación más clara de que esto estaba ocurriendo.

\subsection{Los riesgos y amenazas a la seguridad ciudadana lo son, en gran medida, a la seguridad nacional}

En sus largos viajes por el tercer mundo en crisis, el periodista-politólogo Robert KAPLAN nos anunciaba —ya en 1994- una «anarquía que viene» y que tiene que ver con la inseguridad ciudadana, más que con las guerras tradicionales. Señala cómo una superpoblación tremendamente joven, unida a una importante desestructuración social (familiar, estatal, política), junto con la ausencia de educación, de expectativas, y todo ello en un ambiente de epidemias, pobreza, delincuencia, falta de agua, corrupción, son causas de que muchos países se conviertan en Estados fallidos ${ }^{14}$. Su análisis era certero, si bien tendía a exagerar sus efectos derivados y, con ello, optaba por soluciones demasiado drásticas, de tipo exclusivamente militar y poco dadas a la intervención policial limitada y a la diplomacia con fuerza ${ }^{15}$, como se ve, en cierto modo, en la actuación de los EE UU de Afganistán e Irak (2001-2003), con todas sus secuelas.

Es cierto que ha sido la propia OTAN - inmersa en un proceso de redefinición estratégica provocado por la ausencia de un enemigo militar claroquien ha señalado como riesgos y amenazas para la seguridad de sus países una serie de elementos más policiales y civiles que militares. Y es que, en general, lo que está siendo amenazado no es el territorio del Estado (ámbito clásico de la amenaza militar, de ahí que la seguridad estuviese en las fronteras y que el ejército se situases principalmente ahí) sino su estructura po-

\footnotetext{
13 J. JoRdán y J. L. CALvo, El nuevo rostro de la guerra, cit., pp. 137 y ss.

${ }^{14}$ R. D. KaPlan, Viaje a los confines de la tierra, ediciones B, 1999; y La anarquía que viene, ediciones B, 2000.
}

15 R. D. KAPLAN, El retorno a la antigüedad. La política de los guerreros, ediciones B, 2002. 
LOS NUEVOS RETOS AL MARCO NORMATIVO Y A LA SEGURIDAD EN EL ÁMBITO LOCAL

lítica, su sociedad humana y sus valores, el funcionamiento de las instituciones básicas y el bienestar general de sus ciudadanos. De ahí que, como decía, a la OTAN le preocupen, catalogándolas como amenazas ${ }^{16}$, las siguientes situaciones: incapacidad estatal para gestionar sus propias crisis políticas; corrupción institucional y social; crimen organizado, con numerosos tentáculos en todo el Estado; conflictos étnico-nacional-religiosos; emigración; proliferación (especialmente de ADM químicas, biológicas); seguridad en la información y en los sistemas de recursos básicos (agua, electricidad, etc.); $\mathrm{y}$, por supuesto, el terrorismo.

Como puede apreciarse se trata de una mixtura entre claras amenazas y simples fenómenos reales que pueden ser cobijo de riesgos ${ }^{17}$. Todos ellos tienen un altísimo componente de seguridad ciudadana, aunque, inmediatamente, saltan del mero crimen penal para convertirse en una amenaza para el Estado en su conjunto, por su carácter desestabilizante para la seguridad de éste.

Como puede verse, en definitiva, los conceptos de seguridad y defensa están cada vez más unidos y exigen una actuación conjunta. Actuación que tienda a garantizar lo mayor, eso sí, determinando claramente sus múltiples facetas concretas. Eso es, precisamente, la seguridad, a la que, luego, se podrá adjetivar como se quiera: nacional, ciudadana, personal, pública, etc.

Otro dato real más nos demuestra este melange conceptual. En la actualidad, en el mundo entero, cada vez es más frecuente ver a militares haciendo funciones policiales y a policías que hacen o que colaboran en funciones propiamente militares. De un lado, y basta con ver la televisión, es frecuente ver unidades militares que colaboran en el ámbito interno para realizar labores de vigilancia especial, control de multitudes y de lugares sensibles, apoyo a la policía; y, por otro lado también es frecuente la participación de fuerzas policiales en misiones - militares hasta ahora- de pacificación o de intervención humanitaria. Irlanda del Norte, el plan vigi-pirate en Francia, la vigilancia del espacio aéreo, aeropuertos, metro, etc., en Nueva York y la protección del AvE y otras infraestructuras de energía y comunicaciones, han sido ejemplos de lo primero; las operaciones de intervención humanitaria - y, sobre todo, sus posteriores de estabilización social y política- en Bosnia, Kosovo y Timor oriental, son ejemplos de lo segundo.

¿Es que las cosas están cambiando? En parte sí, pero en parte simplemente lo que esto nos exige es que se reconceptualicen los términos de entendimiento y a que se preste mayor atención a la mutua colaboración. El recelo mutuo - sobre todo el recelo militar a catalogarse como policía por el poco presti-

\footnotetext{
16 C. Donelly, «Replantear la seguridad», en Revista de la OTAN (Invierno 2000-2001), 32 y ss.

${ }^{17}$ Catalogación que, en cierto modo, es muy criticada, sobre todo en cuanto a la inmigración se refiere por muchos politólogos, bajo el prisma del interés creciente que Europa tiene en la inmigración y a que esta visión de la inmigración supone una cobertura para su persecución. Así S. NÄIR, Y vendrán... la inmigración en tiempos hostiles, Bronce, 2006.
} 
gio y honorabilidad que, según ellos, su función y naturaleza tiene; y el policial a ver invadidas sus funciones ${ }^{18}$ - ha de transformase. En fin, lo que resulta claro es que hemos pasado del paradigma de la defensa nacional, cuyo exponente era, claramente, la antigua Ley orgánica de la defensa nacional y la organización militar 1/1980 (reformada en 1984), al de la seguridad nacional. Claro que la nueva Ley de defensa nacional, como luego veremos, no se ha atrevido a este verdadero cambio

\subsection{El ámbito más estricto de la seguridad ciudadana y pública}

Pero volvamos a conceptos más cercanos a nuestros problemas:

Seguridad ciudadana sería la actividad dirigida a la salvaguarda de los derechos y libertades de los ciudadanos, sobre todo frente al riesgo de delitos llamémosles, «comunes» (de ahí que el robo con violencia, los ataques a la propiedad y delitos de ese tipo sean los que más percepción de inseguridad ciudadana provoquen). Su salvaguarda es una función típica de la policía (a nadie que le roben la cartera se le ocurre, por ejemplo, decir que existe un problema de seguridad interior o de orden público...)

Seguridad pública sería, sin embargo, un concepto más amplio, destinado a definir esa misma salvaguarda pero frente a situaciones de mayor riesgo y amenaza (terrorismo, mafias). Porque, sin embargo, al ver estos problemas no se nos ocurre decir que hay un problema de seguridad ciudadana, aunque lo haya, sino de «seguridad pública»o, incluso, de seguridad nacional ${ }^{19}$.

El orden público, en cambio y dejando de lado las connotaciones políticas que este término tuvo, es un concepto muy general, que comprendería a los dos primeros junto con otras muchas actuaciones a las que se dirige el Derecho en general, definido por GUASP como un enorme sistema de salvaguarda y seguridad del orden público ${ }^{20}$.

Estos son, salvo en puntos excepcionales, ámbitos en los que apenas se han producido cambios. Lejanos quedan aquellos momentos en los que eran los ejércitos los encargados de velar por el orden público o en los que éste se hallaba demasiado imbricado con regímenes políticos autoritarios. Nues-

\footnotetext{
${ }^{18}$ Funciones que, durante muchos años, realizaron los ejércitos (M. Balbbé, Orden público y militarismo en la España constitucional, Alianza, 1985). Aunque ya en el siglo XIX los Estados vieron la necesidad de crear fuerzas de policía militarizada (modelo gendármico) que fuesen capaces de dotar al territorio de seguridad ciudadana, pero sin la sobre-fuerza que, normalmente, aplicaba el ejército (D. LÓPEZ GaRrido, La Guardia civil en los orígenes del Estado centralista, Alianza, 2004). Este modelo de policías militarizadas se ha entendido como de gran utilidad para los Estados en construcción y es preconizado por la OTAN para los Balcanes y otros lugares.

${ }_{19}$ Para todo ello, L. PARejo \& R. Dromi, Seguridad pública y Derecho administrativo, Marcial Pons, 2000 , pp. 40 y ss.

${ }^{20}$ J. Guasp, Derecho, Hergón, Madrid, 1981, p. 314.
} 
LOS NUEVOS RETOS AL MARCO NORMATIVO Y A LA SEGURIDAD EN EL ÁMBITO LOCAL

tro país, como Italia y Francia, optó por un modelo mixto de una policía civil y otra militarizada, frente al sistema anglosajón formado por una débil policía civil que necesita ser ayudada por el ejército en numerosas ocasiones $^{21}$. Pues bien, en este entorno la seguridad ciudadana y pública - términos que han sufrido demasiados embates - es el papel prototípico de las FCS. En este ámbito es en el que ese enorme conjunto de policías locales deberían asumir un papel creciente.

\subsection{Las consecuencias sobre las fuerzas policiales y militares}

Ante todo el panorama expuesto JAR CoUSELO se preguntaba qué necesitábamos más si «policías militares» o «militares policías». Lo decía haciendo referencia al cambio en el papel de ambos conjuntos institucionales: FAS y $\mathrm{FCS}^{22}$. El hecho es que si nos fijamos detenidamente a nuestros militares - como ya preconizara JANOWITZ en su señero estudio de 1963 - han estado haciendo en otros países, bajo mandato de la ONU o de la OTAN, en gran medida misiones totalmente policiales, si es que las podemos catalogar así. Nuestros ejércitos y militares son, a un tiempo, guerreros, policías, administradores y diplomáticos ${ }^{23}$.

Pero, a la vez y en parte debido tanto al tradicional tedio que las fuerzas militares tienen por las funciones «policiales» como a la especificidad de las mismas, también se observa el fenómeno contrario. Es decir, nos encontramos con que también en esos lugares se ha llamado a las fuerzas policiales para que acudan a realizar sus funciones específicas una vez las condiciones de seguridad militar son adecuadas (state building). Y resulta que en ese entorno han cobrado especial interés las fuerzas policiales de tipo militar (Guardia civil, Gendarmería, Carabinieri) $^{24}$.

Más aún, en el extranjero las fuerzas militares de algunos países están llevando a cabo verdaderas funciones policiales (patrullaje, controles, persecución de criminales de guerra, investigación forense, desactivación explosivos, control de masas, etc.). A la vez, ante las nuevas amenazas, nuestras fuerzas de seguridad realizan verdaderas funciones de defensa y seguridad militar del territorio e infraestructuras (vigilancia trenes, control espectro elec-

\footnotetext{
${ }^{21}$ G. JAR Couselo, Modelos comparados de policía, Dykinson, 2000.

${ }^{22}$ G. JAR Couselo, «¿Militares policías o policías militares?», en X Seminario Duque de Ahumada, UNED \& Academia de oficiales de la Guardia civil, 1998.

${ }^{23}$ M. JANowitz, El soldado profesional (escrito en 1965), Ministerio de Defensa, 1991.

${ }^{24}$ Papel que ya fue destacado por el propio Duque de Ahumada en el Decreto fundacional de la Guardia civil, al señalar que «ni el Ejército ni la Milicia Nacional desempeñan con la fe necesaria el servicio enojoso de la policía, que aquellos cuerpos miran con cierto desvío por las preocupaciones vulgares, y que sólo se presenta a sus ojos como una obligación pasajera, accesoria y extraña al primordial objeto de su respectivo instituto» (Real Decreto de la Reina Isabel de 28 de marzo de 1844, de creación del Cuerpo de la Guardia civil).
} 
tromagnético, control de masas y fronteras, etc.). Todo resulta enormemente paradójico y tendremos que aceptar que la brillante y tradicional guerra de radiantes soldados uniformados ha sido sustituida - dice LUTTWAK - por las sucias batallas por la seguridad, que son «guerras post-heroicas», poco lustrosas y brillantes, incluso con un medallero más complicado de otorgar ${ }^{25}$.

La colaboración, como veremos, de todas las diversas fuerzas policiales es, a este respecto, imprescindibles Asumir ese nuevo papel y esa necesaria combinación e integración entre seguridad y defensa, entre FCS y Ejércitos es necesaria para nuestra salud nacional, personal e, incluso, psicológica. No queda otra.

\section{El marco normativo ante la seguridad}

\subsection{Constitución y Ley orgánica de fuerzas y cuerpos de seguridad}

Nuestra Constitución es suficientemente amplia como para dar cabida a muy diversos modelos de seguridad ciudadana, cuestión que, por su propia naturaleza y las exigencias operativas debe ser desarrollado, en su modelo, de forma gubernativa y reglamentaria.

Se ha establecido, como modelo general en la LOFCS de 1986, un sistema con varias relaciones: de distribución funcional y territorial entre la Guardia civil y la Policía nacional; locativa y funcional con algunas policías autonómicas y locales; y funcional con una policía judicial dependiente de los jueces (aunque el tenor literal del art. 126.1 de la Constitución de 1978 admitiría una dependencia al estilo americano, del ministerio fiscal). El sistema, muy complejo en algunos puntos, consagra una realidad: la gran parte de las actividades conducentes a la protección de la seguridad ciudadana quedan en manos de las policías «mayores» (Guardia civil, CNP, Ertzaintza y Mossos d'Esquadra, estos dos últimos en su ámbito respectivo). El resto de agentes no cabe duda que velan por ésta, pero no como función prioritaria. Por otro lado, en similar sentido, es el Gobierno central y sus dependencias desconcentradas (las delegaciones y subdelegaciones del gobierno) quienes dirigen de verdad la seguridad ciudadana.

\subsection{La normativa vigente sobre la seguridad}

La Ley Orgánica de Seguridad ciudadana de 1992 es también una norma básica que señala cuáles son los medios y las funciones principales de la policía para ejercitar su actividad de limitación y control de las actividades que puedan vulnerar la seguridad ciudadana. Se trata de una norma suscep-

${ }^{25}$ E. LuTTwAK, «Towards a post-heroic warfare», en Foreign Affairs, 74 (mayo-junio 1995). 
LOS NUEVOS RETOS AL MARCO NORMATIVO Y A LA SEGURIDAD EN EL ÁMBITO LOCAL

tible de varias críticas globales: es poco concreta en algunas potestades policiales (por ejemplo, el uso de la fuerza y, en concreto, de las armas de fuego), le falta de concreción en el elenco de faltas y sanciones. También ha quedado superada por varias cuestiones «modernas» y muy importantes en términos de seguridad ciudadana: inmigración, terrorismo internacional y crimen organizado internacional, y todo lo relativo a las telecomunicaciones ${ }^{26}$. En todos esos puntos sería necesaria una modificación y modernización, pausada pero pronta.

El vuelco verdaderamente importante, que no se ha producido, es en la legislación antiterrorista (Ley de 1984, declarada inconstitucional y reforma posterior de algunos puntos en la LECrim.) ${ }^{27}$. Las nuevas perspectivas nacionales, comunitarias e internacionales le dan una importancia capital. En este ámbito estamos ante un enorme y complejo juego de «paradojas»: Aunque, internacionalmente, se hace de ella una cuestión política entre Estados, partidos, etc.; y, a la vez, se combate por medios policiales (para evitar darle consideración de guerra entre poderes soberanos), cada vez más hay una tendencia a utilizar medios «masivos», de tipo militar (inclusive restricciones de los derechos fundamentales, combate tipo operaciones especiales, ausencia del poder judicial y actuación gubernativa). La paradoja, por tanto, es que no se quiere se convierta en una cuestión política, en cambio es preciso socavar las bases políticas que el terrorismo ha utilizado a su albur ${ }^{28}$, o bien para luchar contra los Estados canallas o santuarios del terrorismo internacional. Este es el caso extremo de los EE. UU: que ha optado por una «guerra total» de tipo militar contra el terrorismo. En tanto que Europa ha optado por una lucha limitada ${ }^{29}$. Creo que en ninguno de los casos los resultados están siendo positivos.

El combate es policial (criminal) pero la evidente disparidad de medios $\mathrm{y}$ fines entre delincuentes-terroristas y fuerzas policiales implica que se trasciende los medios anti-delincuencia para pasar a la lucha contra-subversiva

\footnotetext{
${ }^{26}$ Las célebres «escuchas del CESID» pusieron de manifiesto tanto el difícil papel de un servicio de espionaje dentro del Estado moderno como la falta de una ordenación clara sobre su status (militar o civil), sus fines (defensa o seguridad), funciones y potestades (internas o externas, espionaje preventivo o actividad judicial-criminal). Como se ve son importantes cuestiones. Recientemente se creó el Centro específico de inteligencia militar, adscrito al Estado Mayor del Ejército. También se ha creado un centro de inteligencia policial en el ministerio del interior (Sobre algunos aspectos referidos a sus actuaciones cfrs M. MANZANo SousA, «La interceptación de las telecomunicaciones en la Unión Europea», en Revista Española de Derecho militar 69 (enero-junio 1997), 39 y ss).

27 Cfrs. al respecto el interesante artículo de F. J. BobiLlo, «Constitución y legislación antiterrorista», en Revista de Estudios Políticos 48 (noviembre-diciembre 1985), 47 y ss.

28 y aquí está todo el debate sobre los límites de la democracia o, mejor, de la tolerancia, tan expuestos por la Sentencia del Tribunal Europeo de Derechos Humanos 21 de julio de 2001 asunto «Refah Partisi» o Partido de la prosperidad, que recomiendo leer atentamente. Puede verse un breve análisis de la misma en L. Martín-Retortillo, «La ilegalización del Partido de la Prosperidad Turco o de cómo se conjuró el riesgo de Yihad», en $A B C$ de 21 de abril de 2002, pp. 14 y 15.
}

${ }^{29}$ Para examinar las paradojas de uno y otro sistema cfrs. R. KAGAn, Poder y debilidad, cit., in toto. 
e informativa, lo que, unido a las unas mayores potestades policiales y operativas (alejadas de los clásicos controles judiciales), hace esa lucha más propiamente militar que policial. Además se trata de una lucha internacionalizada, trasnacionalizada y globalizada... implica que estamos ante un nuevo tipo de operaciones militar-policiales (en Afganistán han peleado, cada uno en su peculiar frente, paracaidistas, marines, pilotos de combate, agentes del FBI, expertos de la CIA, soldados de operaciones especiales policiales y del ejército... esto es el futuro de la guerra antiterrorista). Sin necesidad de copiar inmediatamente estos recién experimentados moldes, aún pendientes de apreciar en todas sus consecuencias, habría que pensar en amoldar nuestra legislación antiterrotista a los nuevos retos. Esto exige conocerlos, y conocerlos bien. Pero también exige reinventar un modelo, como parece se esta haciendo en últimas fechas ${ }^{30}$.

Realmente todo este entorno nuevo - interior y exterior - aparece no tanto en las normas policiales, cuanto en documentos como la Revisión Estratégica de la Defensa, teñida de ideas como que las FAS asumen «como tercera y última misión general su contribución, junto con otras instituciones del Estado y Administraciones públicas, a preservar la seguridad y bienestar de los ciudadanos $»^{31}$. Para ello se dotan de una nueva doctrina y formas: proyectables, modulares, integrables, rápidas, flexibles, dotadas de medios que garanticen la primacía en la información, etc. Capaces, en definitiva, de operar en estas guerras asimétricas ${ }^{32}$.

Y es que se ha pasado del paradigma de la defensa (Ley orgánica de la defensa nacional de 1980) al de la seguridad. Pero las leyes no se han atrevido a dar ese paso, de tal manera que la actualmente Ley orgánica 5/2005, de 17 de noviembre, de la Defensa Nacional, no ha querido denominarse «Ley orgánica de la seguridad nacional», que sería más propio; aunque algo haya amagado al respecto. Y así tampoco el Consejo de Defensa Nacional (antes Junta de Defensa Nacional) se ha denominado Consejo de Seguridad Nacional, agrupando además de a las autoridades civiles-militares a las policiales, como habría sido deseable. También es tibio en su tratamiento de las FCS y de las instituciones conjuntas, que se quedan, literalmente, en «agua de borrajas», sin llegar a ningún término realmente serio y aparentemente eficaz.

Queda todo, así, previsto bajo el anticuado paraguas de la Ley orgánica 4/1981, de 1 de junio, reguladora de los estados de alarma, excepción y sitio (en adelante, LOAES). Como es sabido, se trata de una norma prevista

\footnotetext{
${ }^{30}$ El libro más interesante, aunque algo anticuado tras los últimos acontecimientos, es F. REINARES, Terrorismo y antiterrorismo, Taurus, 1998.

31 Ministerio de Defensa, Revisión Estratégica de la Defensa, 2003, III. Las misiones de las FAS, (www.mde.es).

${ }^{32}$ Ministerio de Defensa, Revisión Estratégica de la Defensa, 2003, IV, Las FAS del siglo XXI.
} 
LOS NUEVOS RETOS AL MARCO NORMATIVO Y A LA SEGURIDAD EN EL ÁMBITO LOCAL

para los casos de grave riesgo para la seguridad pública, la población y los valores constitucionales; que, tampoco tiene, no obstante, una regulación sobre un hipotético «estado de guerra». Los dos primeros estados: alarma y excepción, tienen como fin crear el marco para la actuación extraordinaria del poder civil ante diversos tipos de riesgos y amenazas ${ }^{33}$. El primero es una situación de crisis que pone en peligro la subsistencia de la comunidad (al estilo de la crisis argentina actual, por poner un ejemplo cercano). Más «policial» es el estado de excepción en el que la autoridad civil gozaría de amplios poderes policiales y de seguridad (con las Fuerzas Armadas supeditadas a este poder) para evitar riesgos que pongan en peligro, "el libre ejercicio de los derechos y libertades de los ciudadanos, el normal funcionamiento de las instituciones democráticas, el de los servicios públicos esenciales para la comunidad o cualquier otro aspecto del orden público» (art. 13. 1 LOAES).

Se trata de una situación de emergencia nacional que, sin llegar a la guerra (cuya regulación entraría mejor en el estado de sitio), supone o puede suponer un grave quebranto para el Estado. En esa situación todas las fuerzas policiales asumirían un papel muy relevante y necesitarían estar mandadas unívocamente, como así lo prevé la LOAES. También las FAS se someterían al poder especial de mando de esa autoridad civil, como apoyo especial (lo contrario ocurre en el estado de sitio). Claro que la dispersión de las mismas y su relativamente corto número y su especialización dificultaría su despliegue en algunos lugares. Por eso, la propia regulación de los estados de alarma, excepción y sitio, posibilita su localización geográfica y temporal deter$\operatorname{minada}^{34}$.

Pese a las previsiones de todas estas normas, para muchos autores la corrección menor o de «ordinaria administración» (incluso disturbios serios de orden público) del orden jurídico y social quebrantado no es propiamente una actividad limitadora ni sancionadora, pues su naturaleza es la de una acción que vuelve a situar las cosas en su lugar. Se trata de formas coactivas de la policía, principalmente, encaminadas al restablecimiento del orden jurídico perturbado, pues no hay una limitación ante la situación ilegítima (no hay derecho a alterar gravemente el orden público o a conducir temerariamente $)^{35}$. Lo que sí ocurre, y es del todo preciso, es que incluso esa actuación correctora tenga sus límites de proporcionalidad y adecuación. Mientras que las sanciones — también recogidas en la ley con su procedimiento-implican una actividad contraria al ordenamiento pero ya realizada, y no en proceso de ser

\footnotetext{
${ }^{33}$ Para un estudio más completo de estas situaciones, véase: J. M ${ }^{\mathrm{a}}$ LAFUENTE BALle,»Los estados de alarma, excepción y sitio» en Revista de Derecho Político 31 (1990), 27-67; e I. BERdugo GómEZ DE LA TORRE, «Los estados de alarma, excepción y sitio. Comentario a la Ley orgánica 471981, de 1 de junio», en Revista de Política comparada 5 (verano 1981), 99 y ss.

${ }_{34}$ M. Herrero DE MiÑON, «Seguridad y Constitución» en Revista Española de Defensa, mayo de 1995, pp. 68 a 71.
}

35 R. Parada, Derecho administrativo, tomo I, Marcial Pons, 2004, p. 386. 
realizada $^{36}$. La actuación en orden público y gran parte del actuar diario de la policía se enmarcan en esta actividad, aunque den lugar, también y con posterioridad, a procesos sancionadores o, incluso, penales.

Es claro que, hoy por hoy y pese a los problemas de plantilla, la policía actúa mucho más rápido y eficazmente de lo que una corta plantilla de jueces y fiscales aplicando una leyes obsoletas, poco ágiles y nada flexibles, lo hacen. Esto provoca frustración en los policías, impunidad en los delincuentes, e inseguridad en los ciudadanos. Pues son muchos los casos en que los delincuentes, reincidentes o no, están en horas o en minutos en las calles (o incluso en la TV), burlándose de los mismos agentes que los pillaron, quizá in fraganti $i^{37}$.

\subsection{El marco europeo}

No podemos, cerrar el ámbito normativo sin hacer referencia a que Europa es consciente, ya desde hace años, que la política de seguridad ciudadana exige actuaciones conjuntas, unívocas, convergentes entre todos; del mismo modo a cómo el crimen es igual en todas partes. Pero pese a constituir parte del tercer pilar del proceso de construcción europea y a las urgentes necesidad de actuar en esta parcela del Estado, estamos una vez más en un campo en el que "se han consumido más energías políticas en el proceso que en el producto», como señalaría CASTELLS ${ }^{38}$.

Es curioso apreciar que el ámbito más íntimo de la soberanía estatal, cual podía ser la política militar y defensiva se está entregando cada vez más totalmente al nivel supranacional, con la creación de la Fuerza Rápida Europea (o Euroejército) y de una embrionaria PESC. En cambio el arcana imperii de la seguridad interior (que no es tal, como se ha tratado de poner de manifiesto), la información policial y las potestades jurídicas punitivas y procesales se resisten a ser entregadas o, por lo menos, compartidas. Y eso que el lenguaje policial es, creo, el que más fácil podrían entender todos los europeos - y por lo tanto sus agentes de la autoridad - (frente al más esotérico lenguaje militar, judicial o cultural). En efecto, los conceptos comu-

\footnotetext{
${ }^{36}$ Esto se aprecia al examinar las diferencias entre la «devolución en frontera» de los inmigrantes que están tratando de introducirse en nuestro país y los que ya lo han conseguido, cuyo proceso de devolución es mucho más complejo y burocrático.

\begin{abstract}
37 Así lo denunciaba en «Fracasa la estrategia contra la delincuencia» en EL PAIS (domingo 9 de diciembre de 2001), 24. En los años 2000 y 2001 vimos un considerable aumento de los crímenes mayores y menores en todo el territorio y, sobre todo, en Madrid ( $A B C, 27$ de noviembre de 2001). Realmente se trataba de un estallido producido por la sumatoria de varios factores: crecimiento enorme de la inmigración de entrada y tránsito, leyes penales insuficientemente expeditivas, tribunales saturados, prisiones llenas, cambio en los valores sociales, e incluso mayor eficacia policial y judicial en la persecución de los delitos, así como un importante crecimiento de la riqueza nacional, etc. Asimismo está
\end{abstract} volviendo a ocurrir durante los meses de enero a junio de 2006.
}

${ }^{38}$ M. CAStells, La era de la información: economía, sociedad y cultura, cit., p. 24. 
LOS NUEVOS RETOS AL MARCO NORMATIVO Y A LA SEGURIDAD EN EL ÁMBITO LOCAL

nes: hooligans, tironeros, aluniceros, crímenes pasionales, pederastas, violadores y toda la caterva de miserias humanas que dan lugar a los delitos; que son tan viejos como el hombre.

Algo se ha avanzado, y no poco. Desde 1976, las reuniones del Grupo de Trevi han ido dando sus pasos en control de crimen organizado, narcotráfico, vandalismo deportivo. Por ahora se había colaborado por materias, el siguiente paso era la colaboración institucional y funcional, es decir, por estructuras. El SIS (Schengen) operativo, más o menos, desde 1995 esta, poco a poco, teniendo sus frutos en materia de inmigración ilegal, visados y refugiados. El Convenio Schengen III de mayo de 2005 prevé una serio incremento en el intercambio de información entre los países firmantes, con el claro propósito de mejorar la persecución de delitos graves (asesinatos, terrorismo, bandas de crimen organizado, etc. $)^{39}$. Hoy este proceso se ha comunitarizado y sirve, de algún modo, como contrapeso a la libre circulación europea de personas, capitales y servicios. El tratado de Maastrich comenzó la burocratización de las políticas comunitarias en este ramo ${ }^{40}$. Pese al notable avance posterior al 11-M y 11-S y sobre la base de un lento progreso anterior, de nuevo existe la sensación de estar algo parado, aunque funcione ya la euroorden y otras medidas judiciales y policiales intraeuropeas ${ }^{41}$.

El paso fundamental es burocratizar todo sistema de actuación comunitario, dejándolo en manos de organismos europeos permanentes. Estos deben contar con unos sistemas doctrinales y de empleo ya determinados, que no hagan necesaria una reunión de primeros ministros y presidentes cada vez que hay nuevos retos y, menos aún, cuando no los hay. Estas «inercias» o rutinas favorecen la rápida respuesta ante las crisis. La idea, pues, es sustraer el funcionamiento ordinario, y aun extraordinario, de este tercer pilar al voluble voluntarismo propio de las agendas políticas (que existe cuando existe «voluntad política»... peligroso término) y sustituirlo por una regulación administrativa, como ha ocurrido con tantas otras políticas de la UE.

La creación de Europol en 1995 y las posteriores modificaciones hechas en Amsterdam y en Tampere han ido consolidando a esta fuerza policial -que ya tiene misiones, cosa fundamental (pues el problema del Euroejército y otras unidades militares es que no tiene un objetivo estratégico definido ni una autoridad común que las mande, ni unas claras misiones)-. En el año 2000 se ha creado la red europea de escuelas de policía (CEPOL). Ha

\footnotetext{
39 EL PAÍs, 21 de mayo de 2005.

${ }^{40}$ F. REINARES y O. JAIME JiMÉNEZ, «Euroepeización de la actividad policial y lucha contra el terrorismo transnacionalizado», en VV. AA., Aspectos políticos y sociales de la integración europea, Tirant lo Blanch, 1999.

${ }^{41}$ La Euro-orden está vigente desde enero de 2003. Asimismo en agosto de 2002 se pusieron en funcionamiento las primeras comisarías hispano-francesas, patrullas mixtas y equipos de investigación conjuntos. Otro tanto está ocurriendo con Portugal.
} 
sido, también, muy importante, la creación de la Dirección General de asuntos de Justicia e Interior en el seno de la Comisión europea ${ }^{42}$.

Pero no todo es o debe ser policial, la seguridad ciudadana exige, como ya se ha dicho, la actuación judicial unívoca y clara, contundente y correctora (tanto de los hechos delictivos como de posibles desmanes, desviaciones y excesos en la actuación policial), por eso avanzar en procesos como EUROJUST (grupos de fiscales, magistrados y agentes judiciales) o en la orden europea de busca y captura es esencial. Todo ello evitaría una de las autotrabas más grandes que nos hemos puesto los europeos para capturar a nuestros respectivos criminales: los complejos procesos de extradición. Quizá la gran asignatura pendiente sea una mejor red de información y bases de datos policiales (también en el terreno de la inteligencia); aunque en los últimos años la realidad ha obligado a dar grandes pasos en este punto.

\section{La necesidad de una verdadera integración del sistema de seguridad}

En materia de seguridad ciudadana — que es lo que la gente nota- es importante destacar que no siempre la realidad acompaña a la percepción. En efecto, es común que algunos delitos y otras circunstancias racionalmente poco comprensibles, causen una gran alarma social, lo que provoca que se disparen los índices de inseguridad ciudadana percibida o alarmada; aunque esta alarma no tenga una base objetiva ${ }^{43}$. En este punto habría que estudiar cuál es el papel de la prensa, la TV y la radio, cada vez más volcada al estilo «el caso».

Pero, en todo caso, esto nos exige determinar muy claramente cuáles son las causas de los problemas y cuáles son sus manifestaciones más o menos evidentes y permanentes. Porque parece claro que ni los problemas de identidad étnico-cultural, ni las bajas rentas y la pobreza urbanística de algunos barrios, ni la inmigración son, en sí mismos, delitos o matrices exactos de los mismos. Son meras situaciones sociales. Pero si a estas situaciones se les une el analfabetismo, una marginalidad social o una adecuada manipulación política, se convierten en riesgos y amenazas, sobre todo cuando se encuentran adyacentes a islas de riqueza o cuando se unen problemas de integración y educación generacional.

Por eso es fundamental señalar cuáles son las raíces y actuar sobre ellas en la dirección adecuada. Esta viene de la mano de la inversión económica,

\footnotetext{
${ }^{42}$ Para todo ello, L. LuEngo, «Cooperación policial y Europol», en VV. AA., El espacio europeo de libertad, seguridad y justicia, Ministerio del Interior, 2000.

${ }^{43}$ A día de hoy existe una gran alarma social por los delitos que se cometen en España, aunque según los datos oficiales, nos encontramos en uno de los puestos más bajos de la UE en crímenes por habitante, como señalaré más adelante. Para la cuestión de la percepción de la inseguridad cfrs. J. MedinA, «Inseguridad ciudadana, miedo al delito y policía en España», en Revista Electrónica de Ciencia Penal y Criminología 05-03 (2003), en www.criminet.ugr.es/recpc.
} 
LOS NUEVOS RETOS AL MARCO NORMATIVO Y A LA SEGURIDAD EN EL ÁMBITO LOCAL

el favorecimiento del empleo, la desguetización urbanística, la reubicación de grupos culturales de inmigrantes, la educación y la inversión social. No hay otra, pese a que esto suponga una inversión muy costosa y, normalmente, a largo plazo. La seguridad ciudadana no se puede fundamentar en la represión o el hostigamiento, sino que es necesaria la educación previa que evite patologías en situaciones que no pasan de ser normales. Arrancando de raíz los modelos podridos se ayuda a que no se repitan. De otro modo serían campos abonados a otras situaciones matriciales de crimen e inseguridad.

No obstante no hay que olvidar que hay otras actividades delictivas (crimen organizado, narcotráfico) que, de cualquier modo, continuarán existiendo. Y otras que tienen raíces muy complejas como para ser aquí examinadas (terrorismo, asesinatos pasionales). El problema de la inseguridad ciudadana no es estrictamente el de situaciones sociales desfavorecidas, aunque estas contribuyan a que esa inseguridad se produzca.

Desde el punto de vista más técnico son muchos los campos en los que debe actuarse para crear un marco normativo que acoja las medidas más adecuadas para los nuevos y graves retos a los que se enfrenta la seguridad ciudadana en los albores del siglo XXI.

Señalaré algunas medidas que podrían considerarse:

1. Parece necesario mantener una cierta centralización en la normativa, mando, dirección y control de la seguridad ciudadana, sobre todo en cuanto tenga una mediana relación con la seguridad nacional. Y esto por varias razones: la primera de homogeneización del sistema, derivada de la necesidad de dotar de seguridad en los mismos niveles a todas las personas y lugares; la segunda, por eficacia del sistema de información y gestión de la información y lucha antidelincuencia (con unidades especializadas y fuertes capaces de acudir a cualquier lugar, por ejemplo), más coordinado con esta forma de integración que con otras; la tercera porque es un mandato constitucional ineludible que es el Estado a quien le corresponde esta competencia de manera primigenia, tuteladora y directiva.

Uno de los puntos clave, al respecto, es, indudablemente, la integración de las bases de datos. En primer lugar la integración de bases de datos funcionalmente, puesto que es muy frecuente que cada servicio tenga la suya totalmente estanca con la demás. Pero, luego, la integración o, cuanto menos, la cooperación entre los cuerpos. A este respecto estaba previsto que a lo largo de 2005 se unificasen las bases de datos de voces, huellas, ADN, armas y explosivos, alquiler de vehículos y $\mathrm{DNI}^{44}$. Esto es imprescindible y

\footnotetext{
${ }^{44} A B C$ de 29 de noviembre de 2004. Esto es una causa de los atentados del 11-M. Lo mismo ocurrió en los EE. UU. a raíz del 11-S, aunque la mayor complejidad de su modelo ha hecho que el sistema no funcione adecuadamente, tal y como denuncia R. D. Clarke, Contra todos los enemigos, Taurus, 2004, in toto). Así lo exige la Comisión 9/11 en su punto 13. 3. (Congress OF THE U.S.A., The 9/11 final national official comission report on the terrorist attacks upon the united states, Baton Rouge, 2004, pp. 416 y ss.).
} 
quizá pasaría por la custodia de las bases por equipos conjuntos dependientes de un mando independiente al de los cuerpos policiales, así como de unos criterios de acceso y utilización, guiados por la «necesidad de conocer» según nivel y funciones de agentes y unidades.

2. Es indudablemente precisa una colaboración conjunta más adecuada entre las policías (CNP, Guardia Civil, autonómicas y locales) ${ }^{45}$. Al igual que en el nivel europeo con los «equipos conjuntos» en marcha, es hora de ir pensando en equipos combinados españoles en un estadio más avanzado a la propia Policía judicial. Si bien una delimitación competencial es necesaria, ésta no puede ser tan rígida - como se ha demostrado ya en demasiadas ocasiones - para impedir la actuación conjunta o la sustitución de unas fuerzas por otras. En materias de investigación criminal, información, antiterrorismo, redes delictivas, el trabajo común diario resulta obligado. Claro que ello exigiría, entre otras cosas y como primera medida, la homogenización total del régimen retributivo entre cuerpos.

La desaparición de órganos administrativos separados y exclusivos de cada cuerpo cuando cumplen funciones comunes de seguridad, las bases de datos unificadas, etc. debieran estar formadas por personal de ambos cuerpos, evitando redundancias, duplicidades $\mathrm{y}$, así, favoreciendo la desburocratización de la seguridad y la presencia de agentes en funciones administrativas ${ }^{46}$. De otro lado parece preciso necesidad de compartir algunas competencias hasta ahora militares por parte de las FCS (guerra NBQ, control electrónico y de satélites, inteligencia estratégica, espacio electromagnético y redes informáticas, etc.).

3. La entrega de un nivel de competencias en materia de seguridad ciudadana activa en delitos menores (no pasiva, que es lo que hacen) a las policías locales. En este sentido sería precisa tanto una mejor formación de los agentes, como, en otro ámbito, la mayor informatización, automatización y externalización de los servicios de tráfico urbano, de los de mera custodia de instalaciones y edificios públicos, como luego relataré más detenidamente al entrar a la cuestión local. Resulta algo estéril tener cientos de agentes municipales armados en funciones que fácilmente vendrían sustituidas por medios mecánicos: semáforos y señales de tráfico o guardando depósitos de grúa u oficinas de empleo.

Esto no implica un abandono de las fuerzas comunes: Guardia civil y CNP. $\mathrm{Al}$ contrario. El ámbito territorial de la GC es el mundo rural que por su carácter disperso y, en muchas partes del territorio nacional, formado por nú-

\footnotetext{
${ }^{45}$ En este sentido, los análisis del Grupo Español de Estudios Estratégicos (GEES) señala que la una de las primeras prioridades en la política de seguridad ha de ser la creación de un sistema integral, cohesionado y global, tanto en el nivel interno como en internacional: GEES, La reforma del sistema de seguridad español: principios, estructura y elementos de coordinación, análisis n. ${ }^{\circ}$, febrero de 2000 (www.gees.org/articulo/263/).

${ }^{46}$ En este sentido, cfrs también GEES, La reforma del sistema de seguridad español...,: cit., pp. 6-7.
} 
LOS NUEVOS RETOS AL MARCO NORMATIVO Y A LA SEGURIDAD EN EL ÁMBITO LOCAL

cleos muy pequeños de población, exigiría una continuación de la tradicional labor de este cuerpo benemérito. Asimismo ocurre que muchos lugares, por razones de turismo, temporeros, etc., sufren importantes crecimientos esporádicos de la población que exige una mayor presencia policial, que debe hacer en muchos casos la GC. Igualmente ocurre con las aduanas, fronteras, el mar y las carreteras; lugares, todo ellos, que se verían reforzados librando muchos guardias de algunas localidades. Otro tanto ocurriría con el CNP en grandes núcleos de población. Serían unidades de refuerzo, de especialización científica, persecución inter-territorial, etc.

4. Un mejor régimen de protección de la «autoridad policial», que ahora parece un poco endeble ${ }^{47}$. También resulta precisa una clarificación de sus potestades, especialmente en el uso de las armas de fuego. Sería preferible otorgar al agente más margen (que no tenga que llevar el arma con un doble broche de seguridad), pero una mayor exigencia de responsabilidad personal y patrimonial, así como, también, más formación y preparación ${ }^{48}$. Se podrían producir muchos avances, también, en el uso de tecnologías no letales y un mayor entrenamiento en el uso de la defensa y las artes marciales.

Aunque es un terreno ya desarrollado en otros lugares, no está de más insistir en la mayor adecuación de la formación policial a una serie de valores éticos. También un mayor control y exigencia de estabilidad psicológica y comportamental del policía. Cuando se juega con valores (propios y ajenos), con armas de fuego y en actuaciones tan peligrosas como las policiales es exigible un mayor nivel personal (público y privado) al que lo hace, una mayor honestidad. Una numerosa jurisprudencia y el propio tenor literal de algunas normas legales así lo señalan.

5. La regulación restrictiva de la seguridad privada. Pues en cuanto esta toca uno de los elementos soberanos del Estado (velar por la seguridad de sus ciudadanos), sus agentes deben estar dotados de una especial formación y categoría jurídico-pública. Y ser ellos quienes realicen las principales funciones de seguridad. A la seguridad privada habría que limitarla al ámbito de la protección de lugares privados y excluirla de todos los demás. Esto también tendría un efecto beneficioso sobre los números de agentes públicos en el CNP y la Guardia Civil.

6. Parece precisa una mayor imbricación de unidades policiales con la escuela y la universidad. Esto ayudaría a prestigiar las funciones policiales,

\footnotetext{
47 Según datos fiables, hay 65 agresiones diarias contra agentes del CNP y la GC, lo que supone un total de 23.976 agresiones durante el año 2004. Una de las causas es la poca gravedad de los delitos de atentado con la autoridad, resistencia y resistencia a la autoridad en el ejercicio de sus funciones (www.policiajudicial.es, de 25 de abril de 2006, en análogo sentido www.guardiasciviles.com, de 5 de mayo de 2006).

48 Para ello, I. Aguirrezkuega, La coacción administrativa directa, IVAP \& Civitas, 1990; J. BARCELONA Llop, El Régimen jurídico de la policía de seguridad, IVAP, 1988; y L. PÉrez CONEJO, «El uso de las armas de fuego por los agentes públicos: articulación de responsabilidades», en Revista Vasca de Administración Pública 38 (enero-abril 1994), 153 y ss.
} 
a favorecer la educación en estos ámbitos y a encontrar futuros agentes para los niveles inferiores y superiores de las respectivas escalas y cuerpos. La denominada «cultura de defensa» no puede estar desvinculada de la «cultura de la seguridad», tan común en otros países.

\section{CUESTIONES EN TORNO A LAS COMPETENCIAS LOCALES EN SEGURIDAD}

\section{Los retos de la seguridad local}

Pues bien, ¿puede sustraerse a la policía local de todos los anteriores retos? Dice MAYER que la policía es la «actividad del Estado que tiene por fin la defensa del buen orden de la cosa pública mediante los recursos del poder de autoridad contra las perturbaciones que las existencias individuales pueden ocasionar ${ }^{49}$. Este concepto original de policía, más como una función que como un cuerpo, del que parte, en cierto modo, la visión, también originaria, del Estado-policía y, luego, la actividad de policía o limitación del Estado, nos remarca la importancia de que todos los brazos del Estado se involucren en la función policial. Entendido esto como «buen orden en la cosa pública». Y en ese papel es donde el nivel más inmediato al ciudadano debe cumplir un papel mucho más preponderante del que hasta ahora ha tenido, siempre hablando en cautelosos términos generales ${ }^{50}$.

Por ello, en este sentido y aunque las funciones de cada cuerpo policial sean diversas, la primera cuestión que es necesario destacar es la urgencia de realizar una remodelación global de nuestro sistema de seguridad, desordenado, caótico y, en cierto sentido, desaprovechado. Una verdadera integración de las policías locales en él es, hoy día, un requisito ineludible.

\subsection{Las cifras de la (in)seguridad en España}

Los datos son, sin duda, alarmantes. Es de todos conocido el aumento de la criminalidad, pequeña y grande, en la España de los últimos cinco-seis años. Los factores son diversos y no es cuestión de tratarlos aquí (globalización, opulencia económica, descontrol de fronteras, descoordinación en inmigración, terrorismo, asentamiento de mafias extranjeras, etc.). Algunos son tan serios - $\mathrm{o}$ son un foco de inicio de otros tan serios- que la propia OTAN, como ya se indicó, muestra su preocupación. La cuestión, además, no es solamente interna, sino que es una cuestión de «seguridad nacional», como también señalé arriba. No en vano parte de esta delincuencia proviene de esta-

\footnotetext{
${ }^{49}$ O. MAYER, Derecho administrativo alemán, tomo II, De palma, Buenos Aires, 1950, p. 8.

${ }^{50}$ En este sentido, también con matizaciones, J. Barcelona Llop, Policía y Constitución, Tecnos, 1997, pp. 309 y ss.
} 
LOS NUEVOS RETOS AL MARCO NORMATIVO Y A LA SEGURIDAD EN EL ÁMBITO LOCAL

dos fallidos (a los que fagocita) y, a su vez, provoca crisis sociales en otros lugares ${ }^{51}$; en tanto que aquí genera inseguridad local.

Aunque no sea nada fácil encontrar datos completos, ordenados y fiables, y aunque la percepción de la ciudadanía varíe mucho según el lugar y la situación (incluso subjetiva del preceptor de los datos), hay que valorar las siguientes cifras. Más o menos, la criminalidad ha pasado de un 46 por cada mil habitantes (años 1998 y 1999) a un 49 por mil en 2001 (es decir, esto quiere decir casi 700.000 delitos y faltas...) y un 51,5 en su pico de 2002. Junto con una elevación de la delincuencia nacional, también se aprecia una delincuencia asociada al estallido de las cifras de inmigración y al cierto caos en la política relativa a este tema; las fronteras se abrieron y no se controló adecuadamente el proceso, por falta de medios y de una dirección clara. La consecuencia fue una clara elevación en los delitos causados por inmigrantes que llevaron a este importante pico ${ }^{52}$.

En 2003, con un decremento y pese a un serio esfuerzo aún nos encontramos, conforme al año anterior, con: un 5\% más de atracos; 76.000 robos con violencia; 150.000 hurtos; 10.000 estafas; 117 denuncias diarias por malos tratos; y un $4 \%$ más de detenidos (28.000 de los cuales lo han sido en Madrid). Algunos lugares realmente se llevan la palma: Valencia, Granada (ambas alrededor del 100 delitos por cada mil habitantes), Sevilla (un 99 por mil), y Alicante, Ceuta, Madrid, Barcelona, Melilla, Huelva y Castellón ${ }^{53}$, con cifras que rondan el 80 por mil.

Pese al notable aumento de los delitos contra el patrimonio y la libertad sexual, en 2004, se ha producido 3.956.078 expedientes penales incoados por delitos y faltas, lo que supone un decremento de un $0,5 \%$, que se acumula al 2,5\% de decremento en 2004 conforme a las históricas cifras de 2001-2002, años aciagos en la historia de la delincuencia en España ${ }^{54}$. Las cifras publicadas por el Ministerio del Interior en 2006, con respecto a 2005 señalan una importante caída en el número de delitos, del mismo modo a cómo se dice ocurre durante este año 2006. Sin poder entrar a si se trata de un maquillaje, o a cómo y cuánto magnifica la prensa esas cifras de delincuencia, la «sensación» social parece ser de inseguridad creciente (robos en chalets y domicilios, secuestros exprés, violencia doméstica, crímenes en lugares de fiesta, bandas callejeras, etc.), unido a las grandes avenidas de inmigrantes en condiciones precarias.

Lo que resulta nítido es que todo esto tiene una consecuencia inmediata.

\footnotetext{
${ }^{51}$ Fukuyama señala la inexistencia de una aparato burocrático y, en concreto, de seguridad como uno de los factores esenciales para la inexistencia de un Estado verdadero: F. FuKuYAmA, La construcción del Estado, cit., pp. 40 y ss.

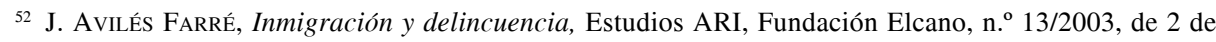
septiembre de 2003 (puede consultarse en www.fundacionelcano.org, área demografía y población).

${ }^{53}$ Fuentes: Ministerio del Interior (www.mir.es), El Mundo y ABC.

${ }^{54}$ Memoria fiscal de 31 de diciembre de 2005 con los datos de 2004 y anteriores (www.justicia.es).
} 
Si en 1982 había alrededor de 20.000 reclusos (y un 35 por mil delitos por habitante) y en 1990 unos 33.000. Los datos de 2004 nos indican que hay ;casi 58.000 reclusos! Esto implica que hay ya un superávit, conforme a las plazas, de casi un tercio, de tal manera que son muchas las cárceles que, actualmente, doblan su capacidad ${ }^{55}$.

Pues bien, no obstante todo ello, somos el cuarto país europeo en número total de policías: la GC cuenta con alrededor de 72.000 efectivos, el CNP con 50.000. En ambos cuerpos se ha frenado la alarmante tendencia a la baja que registraban hace tres-cuatro años ${ }^{56}$. Hay también unos 20.000 policías autonómicos ${ }^{57} \mathrm{y}$, aproximadamente, 60.000 agentes locales ${ }^{58}$. Y ello además de alrededor de los 120.000 agentes privados de seguridad ${ }^{59}$.

Así, dejando de lado el último dato, al no tratarse de agentes de autoridad, todo ello supone la segunda ratio más alta de la UE de policía por cada mil habitantes: 4,8. El primer país es Italia, con 5,2. Muy por debajo está Alemania (3,5), Francia, $(4,1)$, Inglaterra $(3,1)$. Y, en cambio, salvo el caso de Francia - que ha tenido cifras muy altas de delincuencia aunque, no obstante, ha frenado su escalada violenta de los años 1998-2000—, se trata de países catalogados como más seguros en las cifras sociales, aunque la última encuesta del Ministerio del Interior de otros datos ${ }^{60}$.

Con todos estos datos, destaca LiNDE, es fácil concluir que algo no funciona adecuadamente ${ }^{61}$.

\footnotetext{
${ }_{55}$ Memoria de la DG de Instituciones Penitenciarias de 2004.

${ }^{56}$ La convocatoria de 2006 prevé un incremento, conforme a 2005, de un 5,5\%: unos 10.000 policías y guardias civiles, con la idea de mantener el rejuvenecimiento del cuerpo y paliar el progresivo decremento por jubilación, (www.mir.es).

${ }^{57}$ Los Mossos cuentan con unos 12.000 (con intención de convertirse en 15.000 en el año 2020), la Ertzaintza con unos 7.000 y la Policía Foral de Navarra con 700 .

${ }^{58}$ Lamentablemente no he podido encontrar datos fiables al respecto, encontrando cifras que oscilan entre los 50 y los 120 mil. Considerando que solamente la Comunidad de Madrid tiene alrededor de 10.000 y Barcelona capital unos 3.000 parece más idónea la cifra indicada. Según los sindicatos mayoritarios es preciso realizar mejoras laborales en los cuerpos de seguridad local, procedimiento previamente a una reforma de la LOFCS sobre su status; para ellos los policías locales son unos 60.000, cifra que es la que he utilizado (www.csi-csif.es/nacional. en información de 26 de febrero de 2006).

59 Sobre estos últimos, D. CÁmara Del Portillo, «La privatización del orden público. Las policías privadas», en Revista de Derecho de la Unión Europea (RDUE) 7 (segundo trimestre 2004), 357 y ss.

${ }^{60}$ El documento «criminalidad y delincuencia 2005» (que puede descargarse, en 2006, en www.mir.es), señala que la tasa de criminalidad por cada mil habitantes es, por este orden: Inglaterra, 105, 4; Bélgica, 94,4; Dinamarca, 90; Holanda, 85,5; Alemania, 80,4; Austria, 79,9; Francia, 63,9; España, 49,5; Portugal, 40; Irlanda, 23. La media de la UE de los 15 es 70. A mi, sinceramente, estas cifras me chocan y no sé si hay una pauta común de elaboración en todos estos lugares.

${ }^{61}$ E. LINDE, «El servicio público de seguridad ciudadana. Algunas ideas para la coordinación de los Cuerpos y Fuerzas de Seguridad», en Revista de Derecho de la Unión Europea (RDUE) 7 (segundo trimestre 2004), 345 y ss.
} 
LOS NUEVOS RETOS AL MARCO NORMATIVO Y A LA SEGURIDAD EN EL ÁMBITO LOCAL

\subsection{Las competencias locales y su posible reforma}

Parece interesante partir de una base o un planteamiento revisionista de la realidad actual. Creo que es suficientemente conocido el reparto competencial en materia de seguridad, por lo que no me detendré en exponer más que algunas ideas ${ }^{62}$ :

1) Como es perfectamente conocido, al Estado le corresponde la primacía —arts. 104 y 149.1.29 CE - en materia de «seguridad pública».

2) La LOFCS optó por un modelo centralizado, tolerante con los cuerpos policiales de Cataluña y País vasco y Navarra ${ }^{63}$, con cuerpos autónomos de policía que prácticamente sustituyen, en los dos primeros casos, o se solapa, en el tercero, a las FCSE. Otras CC. AA. (Andalucía, Galicia y Valencia) han optado por unidades adscritas del CNP, en funciones limitadas y específicas, en tanto que las demás han preferido mantenerse a la espera ${ }^{64}$. La LOFCS ha sido muy parca y poco concreta con la policía local, convertida en una suerte de paria de la seguridad.

3) Los municipios cumplen algunas funciones de seguridad ciudadana en su ámbito territorial. Con dos ideas que me interesa destacar: la primera, donde el Estado no ha cumplido adecuadamente sus funciones, el municipio ha ido asumiendo de facto algunas competencias y capacidades, aunque siempre dentro de un estrecho margen de actuación y coordinándose a través de las Juntas de seguridad autonómicas. Y, en segundo lugar, el control y la coordinación la ha llevado a cabo (o al menos debería haberlo hecho) la comunidad autónoma respectiva mediante la Junta de coordinación y las competencias que, al respecto, le otorgara con cierta estrechez la LOFCS.

Realmente puede decirse que todo ese marco legal ha quedado ya muy obsoleto, en parte por la poca ambición y el estrecho límite marcado tanto por la LBRL como, luego, por la antigüedad LOFCS ${ }^{65}$. Porque está claro que muchos municipios podrían participar mucho más en la seguridad ciudadana que la mera regulación del tráfico y poco más. Algunos más que otros, eso está claro, por los problemas y costes que tendría todo ello. Y, además, la interlocución por las autoridades de algunas CC. AA., nada interesadas en

\footnotetext{
${ }^{62}$ Para lo que pueden y no pueden hacer, cfrs. L. PAREJo Alfonso, Seguridad pública y Derecho administrativo, cit., pp. 81 a 84 .

${ }^{63}$ Que era, junto con el de Cataluña, el que mejor se justificaba desde un punto de vista histórico, pero que fue mucho más respetuoso con el marco legal que los antedichos: J. C. Alli, «La Administración de la Comunidad Foral Navarra», en La Administración de las CC. AA. (dir. M. Bassols), INAP, 2004, pp. 726 y ss.

${ }^{64}$ Para todo ello, resulta esencial una lectura detenida del completo y agudo libro: J. BARCELONA LLOP, Policía y Constitución, cit., in toto.

65 Sobre todo ello, L. M. DíEz Picazo \& H. LóPez Bofill, «Policía local», en Tratado de Derecho municipal, tomo II (dir. S. MuÑoz MaChado), 2 ${ }^{\text {a }}$ ed., Civitas, 2003, pp. 1541 y ss.
} 
el coste de la seguridad les ha llevado a ser muy pasivas. Los municipios se hallan, ahora mismo, sometidos por una pobre regulación, por la imposibilidad de mancomunar esta función y porque no pueden regular nada, al tratarse de una materia con rango de ley orgánica ${ }^{66}$.

El modelo propugnado por ambas normas no es muy claro y, básicamente, supone que los municipios mayores de 5.000 habitantes deben contar con un cuerpo de policía municipal o local, que realizará funciones de policía administrativa local, guardia y custodia de los bienes, personas y edificios de la localidad, tráfico y seguridad vial, orden público en espectáculos y fiestas locales y, de manera un poco vergonzante, cierta seguridad ciudadana. Claro que esta última previsión choca, inmediatamente, con las competencias de las FCSE, en un régimen muy poco nítido. Porque, a la vez, también es cierto que la autonomía municipal y el propio artículo 25 LBRL exigen que los municipios cumplan sus funciones "pese a quien pese», una de las cuales es la seguridad en sus localidades. Esto ha generado un crecimiento de las policías locales en número y funciones; y la negociación, en los municipios menores a los 5.000 habitantes, de convenios con las policías autonómicas - y así debería ser también con las estatales - para que éstas cumplan esas funciones que la propia LBRL exige. Pero todo queda en una especie de equilibrio precario, hijo de la necesidad y de la improvisación, más basado en las buenas relaciones sociales que en un marco jurídico idóneo, que no existe.

\section{La necesidad de una transformación en la seguridad local}

Por ello es preciso, por tanto, señalar un conjunto de ideas para su transformación y mejora en la línea de revisión que propugno:

1) Reforma de la LOFCS, ya obsoleta, con un nuevo planteamiento de la «seguridad nacional»y, por ende, de la pública y ciudadana y una mejor consideración e implementación de las policías locales, que ya están, sin necesidad de crear unas policías autonómicas ${ }^{67}$. Sería preciso un régimen común más completo para las policías locales, permitiendo a las leyes de las CC. AA. el establecimiento de normas específicas de complemento, únicas para todas sus fuerzas locales ${ }^{68}$.

\footnotetext{
${ }^{66}$ SSTC 25, 49, 50, 51 52, 80, 81, 82, 85, 86 у 156/1993.

${ }^{67}$ En este sentido, también J. Barcelona Llop, Policía y Constitución, cit., pp. 309 y ss.

${ }^{68}$ STC 25/1993, de 21 de enero. Se trataría de salvar, así, todas las inconstitucionalidades hoy presentes con respecto al estatuto de las policías locales cuando sus respectivos ayuntamientos o bien las propias CC. AA. han tratado de regular estos aspectos: habilitación para la movilidad intermunicipal, titulación académica, composición de las juntas de seguridad, autorización para actuación y participación intermunicipal de sus respectivas policías, cuerpos mancomunados o cuerpos supramunicipales, etc. (SSTC 81 y 82/1993, ambas del 8 de marzo, entre otras muchas).
} 
LOS NUEVOS RETOS AL MARCO NORMATIVO Y A LA SEGURIDAD EN EL ÁMBITO LOCAL

Es este, curiosamente, uno de los pocos ámbitos en los que la existencia de un órgano (un cuerpo de policías locales) no ha servido para irse llenando de competencias (como sí ha ocurrido con las policías autonómicas). Creo que la explicación más convincentes puede ser el alto coste y la falta de dinero, así como la descoordinación de los municipios ${ }^{69}$.

2) Dado que no puede garantizarse que los «representantes» de los entes locales en este ámbito, es decir las CC. AA., actúen a favor de esta postura, parece preciso que la FNMC establezca una completa línea de trabajo en el ámbito de la seguridad ciudadana. A resultas de ella seguro que se podrían establecer grupos de municipios, según necesidades, capacidades y ambiciones. Pero esto ya sería algo con lo que empezar.

En las últimas - y únicas- encuestas fiables sobre el nivel de satisfacción con las policías, los mejores éxitos se producen cuando se trata de las policías locales (profesionalidad, moderna, respetuosa, eficaz, imparcial, receptiva, defensora de derechos y libertades), en tanto que, después, venía la Guardia civil y, luego, el CNP; algo querrá decir este estudio ${ }^{70}$.

3) Parece deseable la homologación de las policías locales. Es decir, dado que no se pueden mancomunar los cuerpos sería posible $-\mathrm{y}$ precisa- una mancomunización de su formación, mediante escuelas conjuntas que elevasen su nivel de preparación (quizá con convenios de intercambio con las escuelas del CNP o de la GC), una mayor duración de los estudios, formación específica en seguridad ciudadana, etc. En especial debería atenderse, como ha permitido expresamente el TC, unos sistemas únicos de información recíproca entre las policías locales y la Comunidad Autónoma ${ }^{71}$. Y esto dado que muchas cuestiones estatutarias están congeladas en rango orgánico por la LOFCSE o conservadas en leyes autonómicas.

En esta línea es precisa un mayor apoyo del Estado a las policías locales, mediante programas conjuntos de formación (especialmente de mandos), de operatividad, instrucción, comunicaciones, informática. Todo ello favorecería el mutuo conocimiento y confianza ${ }^{72}$. El aspecto esencial, probablemente, sea la integración de los sistemas de información criminal, cuestión muy compleja no tanto por razones técnicas, cuanto por razones «corporativas» ${ }^{73}$.

\footnotetext{
${ }^{69}$ Me refiero a que el TC ha acabado admitiendo que cuando la Constitución admite la capacidad orgánica de crear cuerpos de policía, esto ha abierto, luego, la puerta al criterio funcional y, por tanto, la transformación paulatina de la «seguridad pública» como algo exclusivamente estatal, en algo compartido en sus «funciones» con las policías autonómicas e, incluso, locales (STC 133/90). Y es que creado el personaje, hay que dotarlo de vida y funciones...

${ }^{70}$ J. Medina, «Inseguridad ciudadana, miedo al delito...», cit. (www.criminet.ugr.es/recpc).

${ }^{71}$ STC 51/1993 y 86/1993, de 8 de marzo.

${ }^{72}$ GEES, La reforma del sistema de seguridad español:..., cit., pp. 12 a 14.

${ }^{73}$ Aun está pendiente la integración adecuada de la información de la Guardia civil y el CNP, así como de la información de cada país en Europol.
} 
4) Es necesaria la conversión de las juntas de seguridad local en verdaderos órganos de dirección y coordinación general de la seguridad local, con primacía de un jefe de policía que dirigiese la seguridad - acción sobre la que pivotaría en el sistema todo lo demás - independientemente del cuerpo al que perteneciese. No puede quedarse la junta de seguridad como un órgano de coordinación ex post facto ${ }^{74}$, sino que debe adoptar una forma proactiva de actuación.

5) La seguridad ciudadana, stricto sensu, podría muy bien quedar encargada a las policías locales, según el modelo norteamericano o británico. Se podrían establecer comisarías y patrullas conjuntas, de cara a aprovechar tanto el diferente ámbito de conocimientos de un policía local y uno nacional, como los medios de éstos últimos (comisarías, calabozos, archivos, etc.). Así lo han hecho, recientemente, las policías francesa y portuguesa. Podría descargarse a las policías municipales de todas las tareas de gestión de tráfico (salvo sanciones, en algunos casos), que bien podría ser encargadas a agentes de movilidad urbana, así como evitar las sobrecargas burocráticas. Muchas funciones bien podrían quedar automatizadas mediante sistemas de videovigilancia y equivalentes.

Todos los planes nacionales de acercamiento y efectividad de la policía han sido siempre de carácter global y nacional, sin tener en cuenta las peculiares realidades locales. Esa es una de las razones de que al menos las tres últimas reformas al respecto hayan cosechado notables fracasos (Plan Belloch, 1995; Plan policía de proximidad, 1997-99; y Plan policía 2000).

6) No parece adecuado, en cambio, de una duplicación de esfuerzos en materia criminal, es decir, en cuestiones de policía judicial estrictamente. Por motivos de preparación, medios, unicidad y efectividad parece más adecuado mantener la actividad judicial en manos del CNP y la GC. No obstante, la anterior idea facilitaría mucho la participación conjunta en investigación de delitos menores en el ámbito local, sin tener que llegar a la junta de seguridad, que a veces es un órgano excesivamente político - y lento de convocar- para los fines que se persiguen.

Los problemas derivados de esta distribución bien podrían pasar por crear un cuerpo nacional de policía judicial, independiente, formado por agentes de todos los cuerpos, pero cuyo régimen de dependencia orgánica perteneciese a un nuevo modelo judicial.

7) Todo lo que ha venido en llamarse «policía administrativa», muy unida, en ocasiones, a ciertos niveles del orden público (deportes, espectáculos, vías públicas, «actividades insalubres, molestas o peligrosas») podría ser trasladado casi en su integridad a los entes locales. No solo me refiero a las deri-

\footnotetext{
${ }^{74}$ Así, también, L. M. Díez Picazo \& H. LóPez Bofill, «Policía local», cit., pp. 1562 y ss.
} 
LOS NUEVOS RETOS AL MARCO NORMATIVO Y A LA SEGURIDAD EN EL ÁMBITO LOCAL

vadas de los bandos y ordenanzas municipales, sino también a todo lo derivado de las normas autonómicas y estatales ${ }^{75}$.

De hecho, la interpretación que el $\mathrm{TC}^{76}$ ha realizado de algunas actuaciones policiales establecidas en la LOSC (drogas, control de vía pública, armas) pueden ser sancionadas, indistintamente, por las autoridades gubernativas $o$ por las locales. También, lógicamente, en los medios, controles, identificaciones, cacheos, etc. Pues la policía local son, obvio es decirlo, agentes de la autoridad.

8) Las FCSE quedarían como cuerpos auxiliares para «policía especial», interregional, antidisturbios, policía científica y criminal, información general, contra-terrorismo y crimen organizado, drogas al más alto nivel, armas y explosivos, operaciones especiales, brigadas móviles, competencias nacionales (DNI, extranjeros, aduanas, fronteras, mar territorial), NRBQ, seguridad informática, bancaria y de las comunicaciones, coordinación internacional, cooperación inter-policial, prisiones y fugados, etc.

La desaparición de muchas unidades y comisarías de las FCS en diversas localidades daría lugar a un incremento y mejora de esas unidades fuertes, especiales o generales. Pero también podría preverse de algún modo la adscripción de policías nacionales a los cuerpos de policía local, así como de material, medios y de los propios edificios ${ }^{77}$.

9) La seguridad privada constituye una forma que, aunque necesaria en algunos casos, resulta lo más contrario al espíritu y la razón de ser del Estado. Por ello debiera quedar como una forma totalmente residual, sometida a un riguroso control y evitando que, como ha sido frecuente, se acuda a ella para funciones de disuasión en seguridad ciudadana (custodia de barrios, urbanizaciones, edificios públicos y lugares de esparcimiento) ${ }^{78}$. Quedaría, por tanto, para la protección de establecimientos privados, bancos, comercios, interior de edificios, construcciones, fábricas, etc.

10) Para la coordinación global sería preciso actualizar las instituciones. Las juntas locales parecen adecuadas, siempre y cuando se conviertan en órganos comunes de trabajo, como se ha dicho. También sería precisa una junta autonómica en la que todos participaran que serviría como correlato al hecho de una mayor participación financiera del sistema autonómico en la

\footnotetext{
75 Y a las relaciones de supremacía especial: F. LóPEZ NiETo y MALlo, La policía municipal, Abellá, 1986, p. 83 y ss.

76 STC 3467/1997, de 8 de abril.

77 Así, también, GEES, La reforma del sistema de seguridad español..., cit., p. 16.

${ }^{78}$ Incluso habría que repensar sus funciones en los aeropuertos, donde quizá podría crearse un cuerpo auxiliar que, bajo directa coordinación de las FCSE realizase esas necesarias y tediosas funciones con un estatuto legal y una imagen —e incluso con un coste- mucho mejor al que ofrecen los cuerpos privados.
} 
seguridad. Finalmente sería preciso establecer una forma más idónea de consejo nacional al previsto en la LOFCS, que no ha funcionado. En cuanto a la financiación sería necesario que las CC. AA. colaboren en el coste de la seguridad local de una manera más plena a como lo hacen hasta la fecha.

\section{EN CONCLUSIÓN}

La policía, en gran parte y desgraciadamente, tiene su razón de ser en la necesidad de reprimir conductas que o no ha sido posible o no se ha podido o no se han sabido prever, o al menos encauzar debidamente. Es decir, que ha fallado o no ha sido posible la acción de policía preventiva que es ese servicio silencioso y disuasorio que realiza habitualmente la policía paseando, recorriendo calles o aldeas o haciendo investigación (¿cuántos crímenes y alteraciones evita esta actuación? no se sabe, pero de seguro que muchos). Entra en juego, entonces, la actuación anti criminal y científica, enmarcada dentro de la actuación judicial. ¿Es admisible a éste respecto tener vigente en el siglo XXI una Ley de enjuiciamiento criminal del siglo XIX llena de petachos, modificaciones y reformas? Y todo un elenco de normas (LOAES, LOFCS, LBRL, etc.) adaptadas a una realidad de Estado-nación, sin amenazas graves a la seguridad, con otro panorama estratégico y político y provenientes de los años 70 y 80 . No parece lógico continuar así, pues esto, como el Código penal, ha de estar suficientemente adaptado a los tiempos, pese a que siempre irá un poco por detrás de ellos.

Al terrorismo, a la gran delincuencia, las mafias, etc. se las combaten de tres formas: No dejándoles la calle libre; permitiendo que la policía criminal y anti-terrorista se sustraiga de la carga de labores de seguridad ciudadana (menor); y, a la vez, evitando que esas graves amenazas a la seguridad nacional, encuentre escapatorias, cobertura, medios y cobijo a través de la delincuencia menor.

De ahí el importante juego que puede hacer la policía local, como factor primario de seguridad ciudadana, en materia de seguridad nacional y, por ello, de seguridad ciudadana. Ese papel, sobre la actividad policial suasoria es el que preconizaba SIR RoBerT PEEL, creador de la moderna policía británica: «El primer objetivo de una policía eficiente es la prevención del crimen; el siguiente la detección y penalización de los infractores si el crimen se ha cometido. Esos son los fines y todos los esfuerzos deben ir a ellos dirigidos. La protección de la vida y la propiedad, la preservación de la quietud pública, la ausencia de crímenes, probarán que esos esfuerzos han sido exitosos, sobre todo si el segundo objetivo no ha sido necesario porque la primera función ha sido alcanzada» ${ }^{79}$.

\footnotetext{
${ }^{79}$ Citado en autor desconocido, The british policemen, London, 1927.
} 